\title{
HUMANISMO: \\ LA PERSPECTIVA \\ NO DUALISTA
}

Franz Oberarzbacher*

\section{¿Qué es el hombre? ¿Qué es ser}

humano? La respuesta que ha recibido esta pregunta está lejos de ser unánime. De hecho, tiene una notable similitud a la que un sacerdote, un pastor y un rabino dieron a la cuestión relativa al uso de las limosnas. El asunto debatido se refería al método idóneo de repartir la limosna entre los respectivos ministros de culto y Dios.

El sacerdote defendía la opinión de que el procedimiento apropiado debía consistir en dibujar un círculo de un metro de diámetro, colocar la limosna en una canastilla, aventarla hacia arriba y, una vez que las monedas cayeran al suelo, tomar para sí las que se encontraran fuera del círculo y destinar a Dios las que hubiesen quedado dentro.

El pastor consideró que en lugar del círculo debía dibujarse un cuadrado de un metro por lado y que, en lugar de tomar para sí el dinero que cayera fuera, quedarse con el que hubiese caído dentro. El resto sería para Dios.

El rabino, objetando que era insensato imponer a Dios alguna restricción, propuso arrojar la canastilla con la limosna y dejar que Dios se tomara, entretanto, la libertad de quedarse con todo lo que quisiera, de modo que para sí mismo quedase sólo lo que eventualmente hubiese vuelto a caer al suelo.

\footnotetext{
* Departamento Académico de Estudios Generales, ITAM.
} 
Al elaborar mi plan de exposición sobre el humanismo consideré conveniente dividirla en tres partes.

Primera parte: un concepto de humanismo que se inspira en una visión no-dualista en sus dos principales modalidades:

a. la místico-espiritualista, que es la menos aceptada y reconocida de cuantos humanismos hay,

b. la materialista.

Segunda parte: algunas versiones de humanismo que arrancan de premisas dualistas, privilegiando la mención de cuatro modalidades, a saber, la del:
a. homo credens
b. homo sapiens
c. homo faber
d. homo dolens

Tercera parte: los Estudios Generales entendidos como requisito moral y ético, y término obligado de referencia de toda sólida formación intelectual.

Sin embargo, la primera parte fue alcanzando una extensión que ya no permitió incluir las otras dos en virtud del limitado tiempo disponible para esta exposición.

Muchos tratadistas de Historia de la Filosofía ${ }^{1}$ están de acuerdo en que el término 'humanista' adquiere, a partir de mediados del siglo $\mathrm{XV}$, la connotación para referirse a quienes enseñaban y cultivaban la gramática, la retórica, la poesía y la filosofía moral. Para los autores latinos, su significado equivalía aproximadamente a lo que los griegos entendían por paideia.

En los dos siglos siguientes se consolida la convicción de que es la antigüedad clásica, tanto la latina como la griega, el genuino cimiento del ideal cultural y educativo.

${ }^{1}$ Giovanni Reale, Dario Antiseri, Historia del pensamiento filosófico y científico, II, 1995, Barcelona, Herder. 
Por otra parte se arraiga paralelamente una perspectiva crítica que pone en entredicho el postulado medieval de subordinar a las grandes sistematizaciones lógico-teológicas las demás áreas de conocimiento. Se promueven, por tanto, estudios puntuales en el ámbito de las ciencias morales, es decir, de la ética, política, derecho, economía, estética y de las ciencias naturales, iuxta propria principia, es decir, con fundamento en su propia legalidad.

Se privilegia además el sentido de la historia y con ella el sentido del poder de objetivación del propio hombre, es decir, de su capacidad de iniciativa y creatividad que se traducen, a su vez, en un repliegue más cuidadoso a su individualidad e intensifica su sentido de responsabilidad.

Brevemente dicho, el humanismo significó la apertura a nuevos horizontes culturales cuya culminación son las celebraciones teóricas de la dignidad del hombre que se identifican con su libertad y su inteligencia y que encuentran sus correlatos visuales en las magníficas obras pictóricas, la escultura, la arquitectura y la poesía.

La genuina prueba de la realidad la aporta de hecho el arte, porque el arte eleva al hombre a su deificación por ser la expresión eminente de su libre poder de acción, de su creatividad, de su originalidad, premisas consideradas decisivas para despertar la admiración, el asombro y la fascinación de sí mismo. Lo que el hombre crea con su acción es su amor, su mundo y su ciencia. El hombre, cuanto más artista es, tanto más verdadero, porque el arte, entendido como actividad metafísica de la vida, es voluntad de apariencia en su forma más elevada, que permite al hombre crecer hasta la suprema plenitud. Y así el hombre ha pretendido restituirse a sí mismo celebrándose solemnemente como el más grande milagro del universo.

En un sentido más lato, no restringido pues a un criterio históricocultural de periodización, puede entenderse por humanismo las más diversas modalidades de la conciencia que de sí mismo tiene el hombre y a la que corresponden ciertos modos fundamentales de concebir y hacer historia. 
El humanismo siempre afronta la tarea, la tarea suprema, de lograr que el hombre se comprenda, y conociéndose, eventualmente también se admire y ame. Entonces, y sólo entonces, habrá alcanzado el hombre la sabiduría.

Pero ciertamente el hombre no se comprende desde sí mismo más que en su relación de copertenencia con el ser, lo que implica y significa instalarse en un horizonte visual que le ha sido designado precisamente como visión del mundo. ¡Sí! En rigor, solamente una visión del mundo posee un régimen de significatividad apto para ser admitido como principio de referencia para edificar la apreciación de la propia existencia y para orientar la convivencia con los semejantes y el entorno. Una visión del mundo, además de ser una forma de conocimiento, es obviamente también una manera de vivir, pues proporciona un principio de direccionalidad a todo individuo y a toda colectividad, y porque cada visión del mundo hace su historia y construye su hermenéutica de la historia con arreglo a sí misma.

Ahora bien, lo decisivo de los diferendos entre cuantas definiciones de realidad o visiones del mundo se postulan, depende precisamente de los modos de concebir y asumir el estatuto de la diferencia misma.

El concepto de diferencia es el punto de partida obligado del que depende la posibilidad misma de una visión del mundo cualquiera, ya sea que se trate de un conjunto articulado de teorías científicas, de sistemas filosóficos, de doctrinas religiosas o mitos. Una distinción fundamental que conviene destacar es la existente entre las concepciones dualistas que postulan que toda diferencia es de naturaleza ontológica, mientras que la no-dualista sólo admite que es de orden epistemológico.

El no-dualismo afirma de modo contundente que el universo es la personificación de Dios, que es Dios que se vive como universo y, por tanto, obviamente también como humano. Un místico como Johann Scheffler (1624-1677), mejor conocido como Angelus Silesius, declara sin ninguna reserva que sólo si me conozco, conozco a Dios. Así que si no me conozco, Dios ciertamente no podría vivir sin mí. ${ }^{2}$ Sólo así la

\footnotetext{
${ }^{2}$ Cherubinischer Wandersmann, 1984, Stuttgart, Reclam.
} 
vida humana se muestra en su verdadera conciencia de sí, es decir, como vida auténtica y de plenitud.

En el Prathyabhijñahrdayam ${ }^{3}$ y en los Shiva Sutras ${ }^{4}$ se dice que el Ser saturado de Conciencia y Libertad extrae de sí mismo todas las formas. No hay ningún poder diferente al del propio Ser que lo obligue a asumir formas, es decir, es el propio Ser quien se autosomete al principio de individuación. Lo hace a partir de su propio Ser y en su propio Ser, pues el Ser no está limitado por un no-ser.

Maya es el nombre que se da al poder de la conciencia para contraerse, es el principio por el cual el Ser multiplica las apariencias y las experiencias de sí mismo. Y porque el Ser se asume como todos los innumerables sujetos y objetos, sus formas de relación no se reducen a otra cosa que a su recíproca adaptación entre sí. Todo lo que hay en el universo existe en un estado de reciprocidad. En rigor, la comprensión de un fenómeno sólo es posible haciendo intervenir la totalidad del universo. Las diferencias entre perceptor, percepción y objeto percibido no son más que el juego del propio Ser que es Conciencia, Libertad y Dicha bajo la apariencia de Maya. Pero de hecho, el que conoce, el medio de conocimiento y lo conocido están perfectamente asimilados en la unidad de la Conciencia pues sólo el Ser es su propio medio para conocerse. Así que conociéndose conoce al Ser, y conocer al Ser es lo mismo que conocerse.

Pero todos estos enunciados parecieran quedar invalidados por la experiencia del sufrimiento del hombre. Uno de los propósitos centrales del Vedanta es, precisamente, descifrar el origen del sufrimiento humano. Y bien, es la ignorancia el origen de su sufrimiento, es decir, cuando un individuo se piensa exclusivamente en los términos de su propia determinación. Por paradójico que resulte, cuando menos sabe el individuo de sí es cuando más firmemente ha afirmado la identificación con su individualidad. Por esta operación y con apoyo

${ }^{3}$ The Secret of Self-Recognition, 1982, Fourth Revised Edition, Delhi, Motilal Banarsidass, [Sanskrit Text with English Translation, Notes and Introduction Jaideva Singh].

${ }^{4}$ The Yoga of Supreme Identity, 1982, Singh, Delhi, Motilala Banarsidass, translated into English with Introduction of Jaideva. 
del principio de contradicción, el individuo se arraiga en la creencia de que su condición es una condición de precariedad óntica extrema. La ignorancia no es sino la falta de entendimiento acerca de la verdadera naturaleza de la mente. La mente es el aspecto del Ser que ha asumido la forma de los objetos externos. Con apoyo de la mente el Ser multiplica las apariencias de sí mismo. En efecto, es la mente el escenario que contiene todos los pensamientos, ideas, juicios con los que se construye la imagen del mundo y la del propio individuo. Por tanto, se sabe lo que es el mundo si se sabe lo que es la mente. De hecho, sin mente no habría mundo, porque no habría ideas, pensamientos, juicios, creencias acerca de él. Tampoco habría finalidad, significados, propósitos, oposiciones entre bien y mal, entre sujeto y objeto, trascendencia e inmanencia, etcétera.

La apariencia del mundo depende de la visión de cada persona. Cada individuo se experimenta de conformidad con la naturaleza de sus propios pensamientos, cada quien vive en un mundo creado por él mismo. Con el pensamiento y la palabra nos donamos un mundo que se convierte en nuestra morada. Cada quien elige la morada que considera digna para sí. La mente, confinada a su aspecto dinámico,

152 no tiene otra alternativa que organizar nuestra experiencia de acuerdo con los principios que gobiernan su naturaleza.

Érase un chacal que animado por su curiosidad de conocer los más variados colores fue de excursión al poblado de los tintoreros. En la banqueta encontró un gran número de cubetas que contenían los más bellos tintes. Repentinamente se tropezó y cayó en una de las cubetas. Una vez que logró salir de su involuntario baño, continuó su camino. Al poco tiempo se vió casualmente en un espejo y quedó gratamente sorprendido al constatar su fascinante transformación. '¡Me he convertido en un pavorreal!', se dijo asombrado, 'iré enseguida de regreso con mis congéneres para exigirles que me rindan los honores propios de mi bello rango'. Una vez que los hubo convencido de que ya no era un chacal sino un hermoso pavorreal... se lo comieron.

Sin embargo, lo decisivo no son los pensamientos como tales. Lo verdaderamente decisivo es sólo la identificación y la apropiación 
de ellos. Es solamente la identificación y apropiación de los pensamientos lo que no permite acceder a la comprensión y experiencia de que lo que es la condición de todo pensamiento no es reductible a ningún pensamiento. La Conciencia es capaz de contraerse como mente reteniendo aún así su naturaleza como Conciencia. La mente es solamente el aspecto dinámico de la Conciencia, es decir, la mente es los pensamientos que se suceden. Pero la Conciencia no abandona por ello su otro aspecto, el estático, pues lo que conoce la sucesión, trasciende toda sucesión, todo tiempo y espacio y toda relación, de otro modo el conocimiento de la sucesión misma sería absolutamente imposible.

El estado libre de pensamientos es la gran luz que consume todas las ilusorias limitaciones. Mientras el hombre permita que su conocimiento esté confinado exclusivamente a lo que es su aspecto dinámico, mientras no lo extienda o dilate a lo que es su aspecto estático, entonces no estará en aptitud de comprender y experimentar que él mismo es el Ser que es Conciencia pura. Tampoco estará en aptitud de comprender que todas las diferencias pertenecen al mismo Ser, que la afirmación del Ser incluye la afirmación del devenir, que el devenir como desarrollo de la diferencia pertenece al Ser.

La poetisa y mística hindú Lalleshwari, al reconocer la identidad entre ella y Shiva exclama: "busqué siempre lo que no soy, hasta que finalmente encontré lo que nunca he dejado de ser. Oh Paramashiva, me preguntaba cuándo habrías de revelarme la verdad. Pero al fin la respuesta está aquí: yo no soy diferente de Ti”.

En un himno a Shiva, que en realidad es un himno a quien lo recita, se dice:

- 'Om. Eso es perfecto, (la palabra 'Eso' alude a lo que no tiene forma, lo que no es representable).

- Esto es perfecto, (es decir, todo lo que tiene forma, los objetos, los pensamientos, los conceptos, las representaciones).

- De lo perfecto surge lo perfecto.

- Si de lo perfecto se quitara lo perfecto quedaría lo perfecto." 
Humano es pues convertirse en amo de la libertad y de la dicha y esta exigencia se corresponde a aquello por lo que el propio hombre se tiene a sí mismo, en cuanto se exige en su esencia de modo sumo.

Sólo cuando hay ignorancia se pone el sentido del Ser fuera del Ser. Sólo cuando hay ignorancia la libertad no se admite a sí misma como su único y supremo bien. Para el no-dualismo el devenir tiene el carácter de acción y de actividad en el sentido de que la acción o la actividad es el Siendo del Ser que genera el encanto del juego, juego que consiste en el espectáculo de oponerse a Sí mismo en sus objetivaciones.

Dicho con los términos utilizados por Nietzsche, Apolo no es sino las infinitas variaciones de Dionisos mismo. En tanto Apolo es el aspecto inmanente de Dionisos, Dionisos es el aspecto trascendente de Apolo.

Dicho también de otra manera, el Absoluto, aunque Espíritu, se muestra como si fuese material; aunque exento de todo condicionamiento se muestra como débil; aunque nada le falta, se muestra como menesteroso; aunque inaccesible a los sentidos, se muestra como tangible; aunque inocente, se muestra culpable; aunque es su propio fin, se muestra regido por deseos. Entonces, a la pregunta de si alguien lo ha visto, la respuesta de quien se ha ejercitado en el discernimiento sería: sí, efectivamente, yo lo he visto viéndome. Pues el actor es a la vez el espectador de todas sus propias representaciones.

Nicolás de Cusa recomienda no limitarse a la forma acostumbrada de razonar que se fundamenta en el principio de contradicción. El principio de contradicción sólo prueba la propia incapacidad de la razón para resolver las contradicciones. La razón es discursiva pues afirma y niega y así instaura siempre relaciones de oposición. En cambio el intelecto capta la coincidencia de los opuestos. Dios es la complicatio oppositorum et eorum coincidentia.

Complicación significa que todas las cosas son Dios en Dios. Por tanto, Dios es la explicación del universo y el universo es la explicación de Dios. Dios se halla contraído en el universo al igual que la unidad está contraída en la pluralidad, la simplicidad en la composición, la 
quietud en el movimiento, la eternidad en la sucesión temporal. Cada individuo es contracción del universo, al igual que éste lo es de Dios. Por tanto, cada individuo es contracción de Dios, es decir, cada individuo resume todo el universo. El hombre es un microcosmos.

También para los gnósticos la disolución de la ignorancia es la tarea suprema del hombre. Las típicas imágenes con las que se alude al extravío del hombre en la ignorancia son el sueño y el ensueño para indicar la confusión entre lo real y lo irreal. La salvación del hombre consiste en recuperar el conocimiento de su divinidad, que no es otra cosa que recuperar lo que él es originalmente.

Cada hombre es el salvador de sí mismo, su salvator salvandus. Las doctrinas gnósticas aparecieron en el conglomerado étnico y religioso del territorio de Siria-Palestina y en el período contemporáneo al nacimiento del cristianismo, aunque independientemente de éste. Se difundieron con gran rapidez y la propia teología del cristianismo primitivo fue influenciada de manera notoria por ellas. Se tienen registrados los complejos vínculos subterráneos con una inabarcable multiplicidad de grupúsculos esotéricos relacionados con la holística, la mística, la magia, el ocultismo, las tradiciones herméticas, incluida la revitalización de la mitología y la alquimia con la escuela de C. G. Jung.

En la acepción jungiana, alquimia es la ciencia de la evolución psicológica que culmina en el inefable Sí-mismo, es el arte de la disolución del conflicto psíquico que permite el acceso a la experiencia de la coniunctio oppositorum. El Sí-mismo no es un postulado teológico ni tampoco metafísico, es un postulado psicológico porque está avalado por la propia experiencia y sólo es accesible por la propia experiencia. Es la experiencia del Espíritu que se confirma en sí mismo.

Sin embargo, el conflicto es la condición de crecimiento hacia la plenitud, es la condición previa que exige un prolongado, difícil y disciplinado entrenamiento en la aceptación de las contradicciones y las tensiones hasta lograr establecerse firmemente en la comprensión de que la Unidad se restaura mediante la reconciliación de los opuestos, porque la unidad es el principio que se exterioriza como diferencia 
reteniendo aún así su absoluta identidad. Ningún árbol niega sus raíces, pues para crecer hacia arriba tiene que crecer también hacia abajo. El Espíritu es una Sicigia, un andrógino alquímico constituido por Logos y Eros, animus y anima, es poder de acción que conoce y ama su poder de acción.

No sería del todo descabellado sostener que la propia ciencia moderna es, en cierto modo, la versión secular del sueño del alquimista y mago cuyo objetivo es la transmutación de la naturaleza en energía. En efecto, la idea de dominar la naturaleza surgió de la tradición mágica y hermética. Más precisamente dicho, es el arte de la numerología lo que conferirá al hombre 'el poder de operar y dominar'.

Con un poco de atrevimiento podría decirse que la numerología es una suerte de parteaguas entre las tradiciones esotérica y exotérica. Desde el punto de vista esotérico se creía que la combinación numérica correcta, la cábala, pondría al adepto en contacto con Dios. Así, por ejemplo, Pico della Mirandola se fascinó con el éxtasis místico a que lo inducía la meditación numérica. Con Francis Bacon se acelera el proceso de la experimentación científica moderna y la tecnología se convertirá en expresión del postulado epistemológico exotérico, lo que se tradujo en la posibilidad de prescindir de las matemáticas en sentido místico.

El denominado no-dualismo materialista es la teoría de que si algo existe, es físico, por tanto, objetos físicos como el cerebro poseen propiedades mentales. Lo mental es lo físico.

Interfaz quiere decir que los sucesos mentales y los sucesos que tienen lugar en el cerebro son exactamente los mismos. El pensamiento es la actividad mental del cerebro. Si la psicología es reductible a la neurofisiología, se impone la exigencia de que lo mental y lo físico se definan con idénticos predicados y no con predicados que se excluyan entre sí, a no ser que libre, activo, intencional, creativo, reflexivo, admirar, imaginar, recordar, sentir, juzgar, valorar, anticipar, subjetivo, inextenso, indivisible, sean asimilables a pasivo, objetivo, extenso, sólido, tangible, divisible, no-intencional. 
Si lo mental es lo físico es necesario que compartan todas, cada una y sólo las propiedades del otro. Que se sepa, la neurofisiología no ha aportado todavía un procedimiento demostrado de verificación que permita establecer la identidad mente-cerebro. Una persona que no estuviera familiarizada con los hechos de su sistema nervioso central, ¿podría acaso estar en aptitud de saber los significados de las palabras, pensamientos y sentimientos que se refieren a sus experiencias? Hacer depender propiedades semánticas de los estados cerebrales supondría admitir que la creencia en los duendes está determinada por la constitución de un específico nodo neuronal en el hemisferio cerebral izquierdo y que la idea del eterno retorno lo es por uno en el derecho.

Sin embargo, el señalamiento de que los sucesos mentales son propiedades físicas en el sentido que nada es la causa de sus propiedades, y que no hay causas mentales de sucesos físicos, pareciera ser una constatación sólida para dar sustento a un conductismo determinista y hedonista. Habría, si acaso, margen para una libertad residual sólo si no necesariamente todo suceso físico fuera idéntico a uno mental. Salta a la vista que este concepto de, si vale decir, humanismo, se inspira fundamentalmente en las ciencias naturales: la física, la química y la biología.

W. Heisenberg, E. Schrödinger, A. N. Whitehead, B. Russell, entre otros, han sugerido las premisas de lo que pudiera llamarse una ontología del suceso.

Materia y mente están constituidos de sucesos sin que sea empíricamente verificable de que lo son. Es decir, se borran los rasgos supuestamente definitorios de materia y mente. Lo que existe no es fundamental ni reduciblemente mental y tampoco material, de hecho no es compatible con ninguna definición. Este planteamiento alude sin duda al noúmeno de Kant. Lo propiamente humano consistiría en un juego de representaciones del que dependerá el destino de la significación y, de ésta, la del hombre. El objeto y su representación se adaptan recíprocamente, es decir, el objeto de hecho cambia según el medio de conocimiento que se haga intervenir y el criterio de selectividad o modelo de abstracción que se adopte. 
Otra importante versión del no-dualismo es la que postula que sólo hay una sustancia que se identifica con la totalidad de lo que existe. La totalidad no admite obviamente ninguna causa externa que la trascienda, así que sólo la totalidad contiene su propia explicación.

Pero, ¿por qué se nos impone entonces con tanta vehemencia la apariencia de individualidad y no la de totalidad? No es Spinoza sino Hegel quien, al sustituir la idea de sustancia por la de sujeto, reivindica, con apoyo de su concepto de dialéctica, la historia y su carácter humanista. La filosofía no puede confinarse ni a la esfera empírica ni tampoco a la esfera metafísica. Tanto una como otra responden solamente a las condiciones de la abstracción. La perspectiva empírica se atiene solamente al conocimiento del fenómeno, sin su concepto, mientras que la perspectiva metafísica se ocupa del concepto, pero sin incluir su fenómeno. Lo cierto es que el Sujeto es Espíritu que se autodesarrolla, es decir, es Identidad que se diferencia sin apoyo de ninguna otra mediación que no sea Él mismo, se auto-opone, se autoaliena y finalmente también se autorrealiza. Es la totalidad de la manifestación de sí mismo. Sólo entonces, tanto la perspectiva subjetiva como la objetiva, se convierten en modalidades de cómo la Conciencia se asume a sí misma como sabida en un juego de correspondencias entre la Identidad que se exterioriza como diferencias y la de éstas reencontrándose en la Identidad.

La tarea de la filosofía es proporcionar una explicación de las diferencias y de las oposiciones, tarea que no tendrá éxito si no se tiene como referencia la totalidad concreta.

A medida que las ciencias empíricas se sometieron a las exigencias de una cada vez mayor especialización y profesionalización, se alejaron más y más de toda referencia a una visión del mundo. Es más, de hecho uno de los efectos más devastadores, en términos de una concepción humanista, fue el que provocó un cierto modo de acometer el quehacer científico que pretendió no sólo prescindir de la referencia a una determinada visión del mundo, sino también, por insensato que parezca, de la referencia misma a quien es justamente su autor. La consecuencia de esta omisión se ha traducido fatalmente en la cada 
vez más frecuente eliminación de la dimensión moral y ética, de suerte que la pretendida autonomía y objetividad de una ciencia así entendida, además de no estar en aptitud de proporcionar de sí misma una definición científica (pues es el sujeto quien tendría que proporcionarla), mucho menos podrá estarlo para comprender y admitir que es siempre el propio hombre quien es la meta final de la ciencia y de la historia. Pero, ¿cómo podría suceder tal cosa si es precisamente el que conoce quien está excluido del conocimiento, y de qué manera podría entonces el sujeto constituirse en objetividad sin cosificarse?

Una ciencia que se asume en estos términos pone entonces en pie, para decirlo con las palabras de Nietzsche, "su propia áspera forma de ataraxia estoica como su última y más seria reivindicación”.

En rigor, toda ciencia, en tanto ontología regional, sólo es saber en la medida que se fundamente metafísicamente y cuando ha comprendido que esa referencia es la condición necesaria para su consistencia esencial.

El postulado deconstructivista, en tanto se propone socavar toda pretensión de fundamentación como fórmula para desafiar cualquier dogmatismo, despotismo y uniformidad, y como contraveneno eficaz para desquiciar los rígidos moldes mentales, es más una invectiva contra la sincronicidad estructural defendida por un vulgar positivismo, pues rechaza que ningún conocimiento puede aspirar a tener validez universal si está basado en un reduccionismo, razón por la que sugiere sustituirla por la diferenciación dinámica y diacrítica.

En los anales de los dioses griegos se destaca la mención de una asamblea en la que se debatió la cuestión relativa al nombre que impondrían al hombre. Las diferentes propuestas nunca pudieron ser avaladas con el beneplácito de la mayoría. Fue finalmente la diosa Cura quien pudo persuadir a todos sus demás colegas de que el motivo de que hubiera tantos desacuerdos se debía al despropósito mismo de semejante iniciativa. Lo que distinguiría al hombre al quedar desprovisto de un nombre es la exigencia de asumir la tarea de descubrirse hasta agotar la totalidad de sus posibilidades. Y una vez llegado ese 
momento, caso de que llegara, podría prescindir, con mayor razón aún, de todo nombre.

Un poco abruptamente, pues faltan la segunda y la tercera partes, quiero concluir diciendo que la formación integral, además de ser una exigencia moral e intelectual, es sin duda también una importante premisa para una sólida capacitación profesional, y es fundamental para toda persona que decida asumir una responsabilidad de dirección o de gobierno en un Estado. La pertinencia de los Estudios Generales se resume en este postulado. 